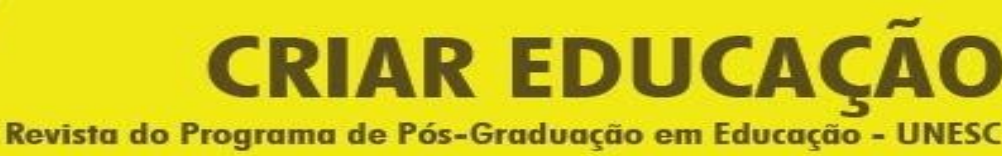

\section{CURIOSIDADE E PRAZER DE APRENDER: O PAPEL DA CURIOSIDADE NA APRENDIZAGEM CRIATIVA}

BERTUNCELLO,Julia Marta Zamarchi ${ }^{1}$ BORTOLETO, Edivaldo ${ }^{2}$

\section{RESUMO}

Este artigo tem por finalidade nos mostrar o que realmente é a curiosidade e qual é sua atuação segundo Assmann. Hoje onde vivemos num mundo globalizado, em que temos uma enxurrada de informações não é difícil de aguçar a curiosidade. Mas esta curiosidade pode ser tanto para o bem como para o mal. Freire e Assmann discutem no âmbito da curiosidade de aprender, de buscar novos conhecimentos além daqueles que the apresentado em sala de aula, a integração docente e discente em sala de aula. Da curiosidade a criatividade é uma das formas de aprender com prazer, incentivar o aluno a buscar novos desafios colocar para fora suas curiosidades. Alunos curiosos não fazem só perguntas, mas vão em busca de respostas. A curiosidade é tão importante quanto a inteligência. A curiosidade prepara o cérebro para aprender, exercita a mente para o novo, ou entender porque algumas coisas aconteceram no passado, buscando novas respostas e indagações. Foi-se o tempo que o individuo curioso era chamado de bisbilhoteiro ou intrigueiro, que apenas algumas pessoas tinha o privilégio de alimentar suas curiosidade e esta

1Bolsista: Graduanda em Direito. Julia Marta Zamarchi Bertuncello, E-mail: juliam_b10@unochapeco.edu.br Curso: Direito, Período: 4 Período.O presente estudo é fruto de pesquisas realizadas pelo Núcleo de Iniciação Cientifica: Cidadania e Justiça na América Latina, da Universidade Comunitária da Região de Chapeco. Bolsa de Pesquisa: Iniciação Científica com recurso do artigo 170 da Constituição do Estado de Santa Catarina.

2Professor responsável pelo projeto: Doutor Programa de Pós-Graduação, UNIMEP. Edivaldo José Bortoleto, E-mail: ejbortol@unochapeco.edu.br 
no mundo contemporâneo faz com que a aprendizagem seja mais prazerosa e aulas menos monótonas.

Hugo Hassmann em seu livro "Curiosidade e Prazer de Aprender", nos leva a refletir sobre vários aspectos e sentidos sobre curiosidade, o que significa propriamente esta palavra em suas diversas formas e idiomas. Como no passado era visto na sociedade a curiosidade? Qual era a relevância na vida do individuo e como foi paulatinamente sendo estuda nas mais variadas teorias e como foi marginalizada diante de pré-conceitos? O autor coloca como "pontochave: é a nova cultura do ensino e da aprendizagem em nossas escolas". Enfatizando que as nossas escolas tem que instigar a curiosidade nos alunos para aprender com satisfação e alegria. Onde o conhecimento se mantém vivo em uma atmosfera leve sem medo das suas escolhas e sem a neofilia (gosto pelo novo).

Nos tempos modernos curiosidade/criatividade é o que está mais em voga no grupos de pesquisas, nas escolas, nos artigos de revistas renomadas. Diante de um mundo globalizado é impossível que este sentimento não seja aflorado pelo mundo escolar, acadêmico e na sociedade num todo.

"Em síntese, a curiosidade propícia "atitudes mais saudáveis"” (HASSMANN, 2004, p.18).

Porém o que é curiosidade? No dicionário escolar Michaelis - curiosidade - (lat curiositate), qualidade de ser curioso; desejo de desvendar, saber ou ver, indiscrição, objeto raro ou indiscrição.

Hassmann at ali, Gelber em uma de suas frases "Curiositá: todos os seres humanos nascem com o desejo de aprender.

São termos comuns e indefesos, como a maioria das palavras não complicadas. Tem tradução literal e sem problemas no idiomas neolatinos: cruiosidad, curiosità, curiosité (desconheço o romeno e outros parentes); e até no inglês: curiosity.(HASSMANN, 2004, P. 23).

Criar Educação, Criciúma, v. 6, n², julho/novembro 2017.- PPGE - UNESC 


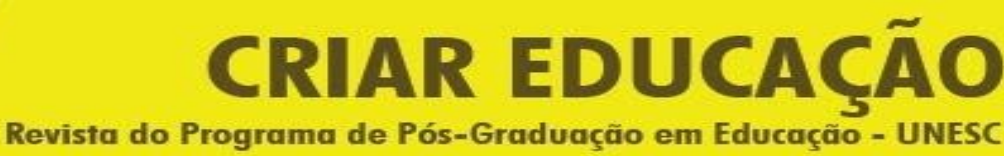

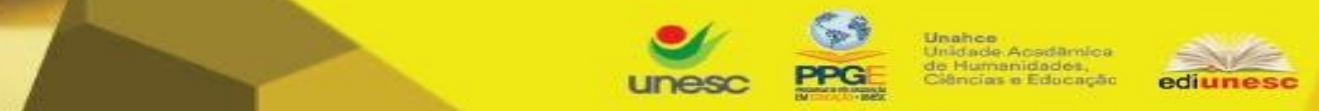

A curiosidade tem que ser instigada para que novas descobertas sejam feitas, os alunos tem que ter esta liberdade para expor suas curiosidade mas sempre sem invadir a privacidade do outro, o professor não simplesmente cuspir seu conhecimento como uma verdade acabada, mas deixar a interrogação para que a curiosidade vai além, que sua aula seja um espaço para desbravar novos conhecimentos nos livros, jornais, revistas e nas novas tecnologias que estão aí fazendo parte do nosso dia a dia.

Paulo Freire em sua obra "Pedagogia da Autonomia", em um capitulo especifico fala o quanto é importante a curiosidade em sala de aula, na vida das pessoas. Não podemos engolir aquilo que nós édespejados como uma verdade única, que devemos ir além, ser curioso mesmo nas nossas curiosidade.

\footnotetext{
O exercício da curiosidade convoca a imaginação a intuição, as emoções, a capacidade de conjecturar, de comparar, na busca da perfilização do objeto ou do objeto ou achado de sua razão de ser. Um ruído, por exemplo, pode provocar minha curiosidade. Observo o espaço onde parece que se está verificando. Aguço o ouvido. Procuro comparar com outo ruído cuja razão de ser já conheço. Investigo o espaço. Admito hipóteses várias em torno do possível origem do ruído. Elimino algumas até que chego a sua explicação. (FREIRE, 2006, p. 88).
}

A curiosidade também pode ser vista como xeretice, fofoca, meter o bedelho, maus hábitos. Mas devemos avançar no conceito que no passado ao longo da história se tornou tabu. No passado não muito distante, a criança curiosa era vista como alguém bisbilhoteira, de caráter duvidoso e muitas vezes repreendidas pelos pais e professores. Assim tolhendo a sua sede de conhecimento e de aprendizagem. O desenvolvimento de uma criança se dá na curiosidade, por exemplo, desmontar um brinquedo para ver porque ele funciona daquela forma, o pegar o objeto na mão para sentir suas formas, o rasgar uma revista, para ouvir o barulho do papel rasgando. A curiosidade é o desenvolvimento da inteligência da criança, do individuo em sua formação. A 
vontade de aprender vem da "curiosidade", sem este ingrediente não é possível fazer que haja interesse no que está pretendendo conhecer e aprender.

No século XVIII, as mulheres eram castigadas e até queimadas diante da curiosidade em que se tinha em determinados assuntos, era o patriarcalismo que dominava o interesse pelo novo ou pelo desconhecido. Uma palavra que aguçou-me a curiosidade foi "vilipendio", que nada mais é o significado de menosprezo, desrespeito para com alguém ou alguma coisa. $\mathrm{E}$ o vilipendio foi em dose dobrada para com as mulheres no passado e nos dias de hoje ainda é praticado pela sociedade machista e preconceituosa da nossa comunidade contemporânea.

Paulo Freire foi o mestre dos mestres, mudando a percepção dos educadores, levando à eles uma nova perspectiva didática no ensino aprendizagem. Num mundo capitalista onde as ferramentas inovadoras e tecnológica são privilégios de poucos, Freire propunha e aplicava era promover um processo educacional a partir do repertório/experiência do educando, politizar os processos de educação e comunicação, pressupondo um educador politizado e ativo que estimula o educando a conquistar sua liberação em sua simplicidade foi a fonte de inspiração para o professor. Diante da precariedade da formação dos docentes no Brasil, a TV se tornou uma ferramenta potencial de comunicação com os alunos. O rádio também tem uma força maior de comunicação e oralidade das populações marginalizadas.

Numa era do conhecimento globalizado não cabe mais uma aprendizagem enlatada, pronta, padronizada. Os professores tem que ter mais diálogos com seus alunos, ouvindo-os, aguçando a curiosidade deles, fazendo com que eles mesmos sintam curiosidade de suas curiosidades. Questionando, usando todas as ferramentas possíveis e imagináveis para que possam ver além daquilo que Ihe é proposto. 
Aprender com curiosidade a aprender - é o despertar do prazer de conhecer, de compreender, descobrir, construir e reconstruir o conhecimento, ter curiosidade. É habilidade a ser desenvolvida sempre, ao longo de toda a vida, a fim de compreender o mundo, a sociedade, o movimento das ideias; é a busca do conhecimento, onde ele se encontra, principalmente hoje com toda a tecnologia disponível. (HASSMANN, 2006, p. 39).

O professor ou o educador apesar de toda a desmotivação do Estado tem que reencantar a educação, para que desperte a curiosidade de aprender do educando. O que significa reencantar a educação? Seria uma nova forma de educar e de aprender? Encantar, segundo o Novo Dicionário Aurélio (1999:745) significa cativar, seduzir, maravilhar, arrebatar, lançar encantamento e magia sobre algo, causar prazer, transformar em um outro ser. Reencantar seria, então, voltar a seduzir, a cativar novamente, a transformar mais uma vez. Encanto traduz a idéia de sedução, beleza e magia. É algo que nos fascina e nos deixa maravilhados. E a educação? O que é que ela tem a ver com tudo isto?

[...]O reencantamentoda educação requer a uniãoentre sensibilidadesocial e eficiência pedagógica.Portanto,ocompromisso ético-políticodo/aeducador/adeve manifestar-se primordialmente na excelência pedagógica e na colaboração para um clima esperançador no próprio contexto escolar.Educação e seduçãoRubensAlvescostumadizerqueeducartemtudohavercoma

sedução. Segundo ele,educador/a équemconseguedesfazeras resistências ao prazer do conhecimento.Seduzir parao quê?Ora para um saber/sabor. Portanto, paraoconhecimentocomofruição. Mas é importante frisar igualmente "para quem", porque pedagogia éencartarse eseduzir-sereciprocamentecomexperiênciasde aprendizagem. Nosdocentesdevetornar-sevisívelogozodeestar colaborandocomessacoisaestupendaqueépossibilitar e incrementarnaesferasócio-cultural,queserefletediretamentena esferabiológica -auniãoprofundaentreprocessosvitaise processos de conhecimento (ASSMANN, 2000, p. 34).

Não se pode mais apenas seguir convenções ou padrões didáticos num mundo globalizado, o aluno de hoje que ir muito mais além do que os livros didáticos e conteúdos passados na lousa. $\mathrm{O}$ docente tem que seduzir $\mathrm{O}$ 


\section{CRIAR EDUCAÇÃO}

Revista do Programa de Pós-Graduação em Educação - UNESC

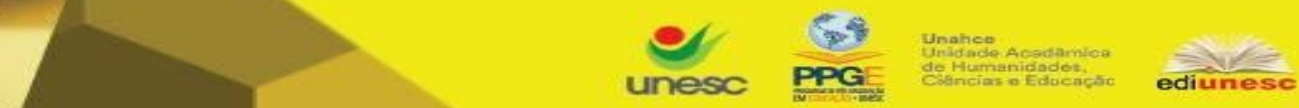

discente para despertar esta curiosidade que está lá no seu intimo adormecido, esperando apenas a oportunidade de aflorar em busca de repostas diferentes do que aquelas que lhe foi dada.

Conclusão

O futuro pertence aos curiosos, são eles que vão trazer novas respostas, fórmulas, conceitos lincados com o mundo. O grande mestre Paulo Freire tinha uma preocupação com a educação, que não fosse convencional, que os docentes tivessem suas vasilhas do conhecimento cheio, para que pudesse aguçar a curiosidade dos discentes. Levar os alunos além daquilo que era proposto em uma emenda curricular. Assmann também se mostrou preocupado com a educação, onde os alunos entediados com uma rotina de sala de aula e assuntos pré-estabelecidos. No mundo contemporâneo a curiosidade se faz frente a uma gama de informações que não for bem orientada pode levar ao equivoco, informações distorcidas, a tecnologia e uma ferramenta que veio para ajudar, mas se não souber usar poderá se ferir gravemente, ou até mesmo expor a situações nada agradáveis. A pedagogia deve estar preparada para estas pluralidade de conhecimentos sabendo fazer a triagem para despertar a curiosidades de seus alunos.

\section{Bibliografia}

Criar Educação, Criciúma, v. 6, n², julho/novembro 2017.- PPGE - UNESC 
Assmann, Hugo, Curiosidade e Prazer de Aprender - O papel da curiosidade na aprendizagem criativa. - Petropolis, RJ: Editora Vozes, 2004.

Freire, Paulo. Pedagogia do oprimido, $17^{a}$ ed., Rio de Janeiro: Paz e Terra, 1987.

_. Pedagogia da autonomia: saberes necessários à prática educativa, $33^{a}$ ed., São Paulo: Paz e Terra, 1996 (Coleção Leitura). 